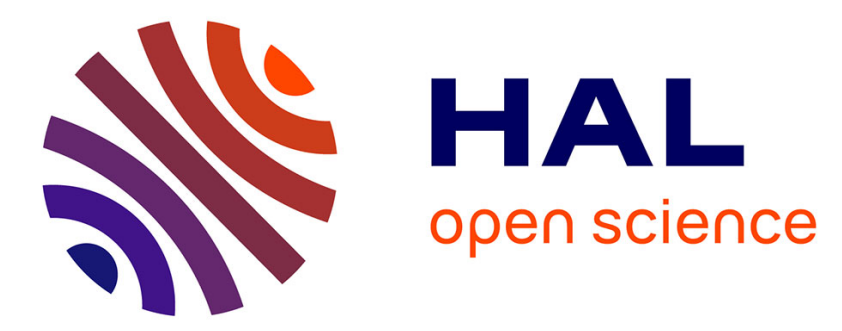

\title{
Artificial buzzing lips and brass instruments: Experimental results
}

Joël Gilbert, Sylvie Ponthus, Jean-François Petiot

\section{To cite this version:}

Joël Gilbert, Sylvie Ponthus, Jean-François Petiot. Artificial buzzing lips and brass instruments: Experimental results. Journal of the Acoustical Society of America, 1998, 104 (3), pp.1627-1632. 10.1121/1.424375. hal-01878544

\section{HAL Id: hal-01878544 \\ https://hal-univ-lemans.archives-ouvertes.fr/hal-01878544}

Submitted on 14 Jun 2019

HAL is a multi-disciplinary open access archive for the deposit and dissemination of scientific research documents, whether they are published or not. The documents may come from teaching and research institutions in France or abroad, or from public or private research centers.
L'archive ouverte pluridisciplinaire HAL, est destinée au dépôt et à la diffusion de documents scientifiques de niveau recherche, publiés ou non, émanant des établissements d'enseignement et de recherche français ou étrangers, des laboratoires publics ou privés. 


\title{
Artificial buzzing lips and brass instruments: Experimental results
}

\author{
Joël Gilbert and Sylvie Ponthus \\ Institut d'Acoustique et de Mécanique de l'Université du Maine, Laboratoire d'Acoustique-UMR CNRS \\ 6613, Avenue Olivier Messiaen, 72085 Le Mans Cedex 9, France \\ Jean-François Petiot \\ Institut de Recherche en Cybernétique de Nantes, UMR CNRS 6597-Equipe CMAO Productique, \\ 1 rue de la Nö̈, BP 92101, 44321 Nantes Cedex 3, France
}

\begin{abstract}
Experimental results of a special artificial trombone player are presented: A mechanical device is a substitute for the musician. Wind instruments, and particularly the brass, are self-sustained oscillators. The oscillations are induced by a mechanical oscillator (the lips of the player) acting as a valve which modulates the flow. Measured mechanical parameters of the artificial buzzing lips for different "embouchures of the player" are presented, and analyzed in connection with the played frequencies obtained for the same "embouchures." The results are obtained with two resonator systems (a mouthpiece alone and a trombone with its mouthpiece).
\end{abstract}

PACS numbers: 43.75.Fg [WJS]

\section{INTRODUCTION}

Oscillations of wind instruments, and particularly lipdriven wind instruments (the brass), are driven by selfsustained oscillations of an air flow. These oscillations are induced by a mechanical oscillator (the lips of the player), acting as a valve which modulates the flow. The destabilization of the mechanical element is the result of a complex aeroelastic coupling among (1) the lips, (2) the air flow entering the instrument as a result of the static overpressure in the mouth of the musician, and (3) the resonant acoustic field in the instrument itself. The brass instruments have been extensively studied (see, for example, Backus, 1976; Pratt et al., 1977; Elliot et al., 1982; Causse et al., 1984). A global study including the player behavior has been proposed by Elliot and Bowsher (1982). In the last 10 years, time-domain simulations based on this kind of model have been proposed (Strong and Dudley, 1993; Dietz and Amir, 1995; Adachi and Sato, 1996; Rodet and Vergez, 1996; Juin, 1996; Msallam et al., 1997). Due to the essential nonlinearity of the governing equations describing the mechanical behavior of the lips coupled with the air flow entering the instrument, it is important to focus our attention on this part of the system. Some experimental results focused on the human lip oscillations have been obtained: Martin (1942); Elliot and Bowsher (1982); Saneyoshi et al. (1987); Yoshikawa (1995); Bailliet et al. (1995); Chen and Weinreich (1996); Copley and Strong (1996). One of the major difficulties of this kind of experimental study on vibrating lips is the human player. In order to avoid this major difficulty, we have decided to develop an artificial mouth for brass using artificial buzzing lips.

Previous studies on reed musical instruments (Backus, 1963; Wilson and Beavers, 1974; Meynial, 1987; Gilbert, 1991; Idogawa et al., 1993; Gazengel, 1994; Dalmont et al., 1995) have demonstrated the usefulness of a mechanical de- vice as a substitute for the musician. This substitution allows stable mouth controls and makes it possible to take extensive measurements during stable playing conditions and to compare these with characteristic features of the instrument. We will present here comparisons of the playing frequency near the threshold of oscillations, the acoustical passive resonance frequency of the instrument and the mechanical passive resonance frequency of the lips. After a first artificial mouth for brass instruments (Gilbert and Petiot, 1997a, b) was developed in order to measure the effect of nonlinear propagation in the instrument (Beauchamp, 1980; Hirschberg et al., 1996), a second one (Piau, 1997) has been constructed with improved control of the embouchure, and the latter has been used in the experiments described in this paper.

The present paper is divided into three parts. After this brief Introduction, we present the experimental setups in Sec. I: the artificial mouth setup, the input impedance measurement, and the artificial lips' mechanical characterization are described successively. Different frequencies are obtained from these setups (Sec. II): the acoustical resonance frequency (Fres) from the input impedance measurement, the lips' eigenfrequencies (Flip) from the mechanical characterization, and the played frequencies (Fplay) by playing the instrument with the artificial mouth. By controlling the "embouchure" of the artificial mouth, the lips' frequencies and the played frequencies are slightly modified. The measurements are reported twice: first with a mouthpiece alone, second with the entire trombone including its mouthpiece. Finally the experimental results are analyzed.

\section{EXPERIMENTAL SETUPS AND PROCEDURES}

\section{A. Artificial mouth and buzzing lips}

The artificial mouth (Fig. 1) consists of a hermetically sealed box (volume $1500 \mathrm{~cm}^{3}$ ) fed by a high-pressure (5-bar maximum) air supply. The mouth pressure in the box is con- 


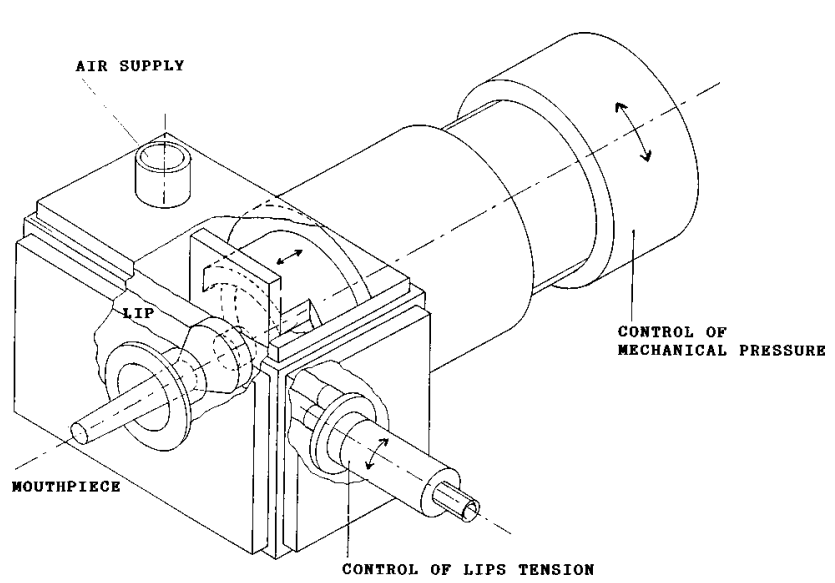

FIG. 1. The artificial mouth for brass instruments.

trolled by a pressure regulator. A $1 \mathrm{~m}$ long tube of $1 \mathrm{~cm}$ diameter connects the regulating valve to the artificial mouth. The "artificial lip" is a latex tube filled with water. The lip is $150 \mathrm{~mm}$ long, with a diameter of $16 \mathrm{~mm}$, and a wall thickness of $0.6 \mathrm{~mm}$. It is constrained by an "artificial jaw", consisting of a plate with a circular hole of $2 \mathrm{~cm}$ diameter (Fig. 1). The lip is pressed by the mouthpiece against the "jaw." There are two mechanical control parameters for the embouchure: a control of the lip tension, and a control of the position of the mouthpiece relative to the lip. Thus the " $\mathrm{em}$ bouchure,' the way the mouthpiece and lips interact, is controlled by the intrinsic parameters of the lips such as the tension of the latex tubes, the mass of water inside, and the position of the mouthpiece relative to the lips. The last is the only parameter used to vary the embouchure for experiments presented in Sec. II.

There are minor differences with respect to the first version of the artificial mouth described in Gilbert and Petiot (1997a, b). The mechanical system of the embouchure is moved from the front to the back of the mouth; the mouthpiece is clamped and remains fixed. Therefore it is possible to replace one brass instrument with another without perturbation of the embouchure. In the experiments described here, to have a mechanical system as simple as possible, only one latex lip is installed, the other being replaced by a solid plate. The artificial mouth has a realistic playing performance, as judged by listening to the sound produced by the system. Notice that such a single lip drive has already been used by Gokhstein (1981) for observations on human lip oscillations.

\section{B. Resonator input impedance}

\section{Input impedance measurement}

The air resonator system, a mouthpiece alone or a trombone with its mouthpiece, is characterized by its input impedance (complex quotient of the acoustical pressure and volume velocity in the input of the resonator in forced oscillations). The input impedances are measured by the apparatus described in Dalmont and Bruneau (1991). The apparatus is a simple plane support for three microphones (including one microphone acting as source) and the object to be measured. In practice, an adaptator needs to be custom-made to fix the object to the support. Within the measuring probe an


FIG. 2. The measured input impedance of the trombone (Courtois model 149) with its mouthpiece (Bach model Megatone $6^{1 / 2} \mathrm{AM}$ ). The value of the impedance magnitude (decibel representation) is expressed in units of $\rho c / S$ (the characteristic impedance of the air in the pressure-volume velocity analogy, $S$ is the input cross-sectional area of the mouthpiece). The value of the impedance phase is expressed in radian.

electrostatic transducer (1/2-in electrostatic microphone cartridge $\mathrm{B} \& \mathrm{~K})$ is used as a source and two electret microphones (electret microphone cartridges, Sennheiser KE4) are used as receivers. The two receivers are placed in the same plane as the emitter on either side and diametrically opposite each other. Notice that for our application we only use one of the two receiving microphones. The second one is useful when measurements of the first helical mode are performed (Dalmont and Bruneau, 1991). Our impedance measurements are done below the first cut-off frequency, so that the plane-wave propagation approximation is accurate.

The impedance measurements shown below are made with a harmonic source. The transfer function (microphone signal over excitation signal) is obtained by a dual-phaselock-in technique. The frequency range of the swept sine is typically 20-1000 Hz. Before the measurements we use a method of calibration based on preliminary measurements with a set of closed cylindrical tubes [for further details, see Dalmont and Bruneau (1991)].

\section{Results}

Figure 2 shows the measured input impedance of the trombone (Courtois model 149) with its mouthpiece (Bach model Megatone $6^{1 / 2} \mathrm{AM}$ ). The impedance curve is comparable with, among others, the experimental results of Elliot and Bowsher (1982). The parameters (frequency, quality factor, magnitude) of the eight first resonances are given in Table I. Moreover the input impedance of the trombone mouthpiece alone has been measured. As expected, the mouthpiece has only one resonance frequency (frequency corresponding to a magnitude maximum and a zero phase of the input impedance): the resonance frequency is $\mathrm{Fm}$ $=545.6 \mathrm{~Hz}$, and the quality factor of this resonance is 19.9 .

We will use in our further discussion the following resonance frequencies for comparison with the other frequencies: the resonance frequency $F m$ of the mouthpiece $(F m$ 
TABLE I. Frequency $(\mathrm{Hz})$, quality factor (dimensionless), and magnitude $(\mathrm{dB})$ of the eight first resonances of the trombone (Courtois model 149) with its mouthpiece (Bach model Megatone $6^{1 / 2} \mathrm{AM}$ ).

\begin{tabular}{cccc}
\hline \hline $\begin{array}{c}\text { Resonance } \\
\text { number }\end{array}$ & Frequency $(\mathrm{Hz})$ & Quality factor & Magnitude $(\mathrm{dB})$ \\
\hline 1 & 38.1 & 8.4 & 25.5 \\
2 & 111.3 & 18.1 & 23.9 \\
3 & 169.1 & 19.8 & 22.2 \\
4 & 228.2 & 24.6 & 21.6 \\
5 & 290.8 & 24.9 & 22.4 \\
6 & 343.3 & 34.6 & 22.1 \\
7 & 399.2 & 31.1 & 18.4 \\
8 & 458.1 & 28.0 & 17.5 \\
\hline \hline
\end{tabular}

$=545.6 \mathrm{~Hz}$ ), and the resonance frequencies number 3, 4, 5 of the trombone $(F t 3=169.1 \mathrm{~Hz}, F t 4=228.2 \mathrm{~Hz}, F t 5$ $=290.8 \mathrm{~Hz}$ ).

\section{Artificial lip mechanical response}

\section{Mechanical response measurement}

The aim of the experimental setup described below is to allow a mechanical characterization of the embouchure (the lip and its boundary conditions imposed by the position of the mouthpiece). The mechanical response of the lip is obtained by simultaneous measurement of lip vibration (using a laser vibrometer Polytec OFV 3000) and the acoustic pressure in the mouth behind the lip and the jaw (using an electret microphone cartridge, Sennheiser KE4). The lip is excited in forced oscillation by a sound source (a compression loudspeaker driver, JBL model TRS001). The mechanical response (vibrometer displacement signal over mouth pressure signal) is obtained by means of a dual-phase-lock-in technique (Fig. 3). The frequency range of the swept sine is typically 50 to $500 \mathrm{~Hz}$.

The source is positioned behind the lip; we assume that the pressure there is locally uniform, and representative of

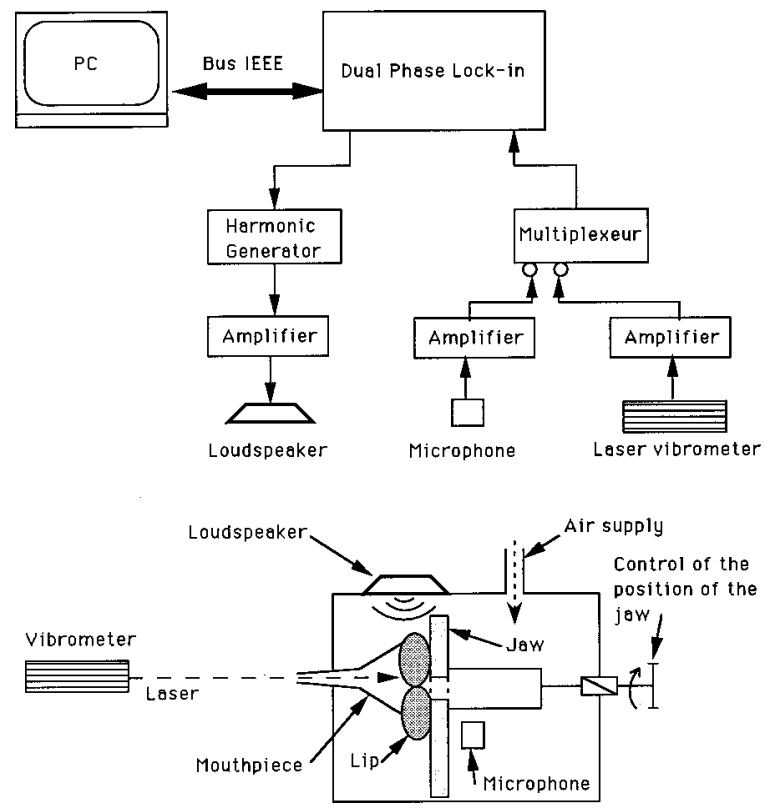

FIG. 3. The mechanical response measurement setup.

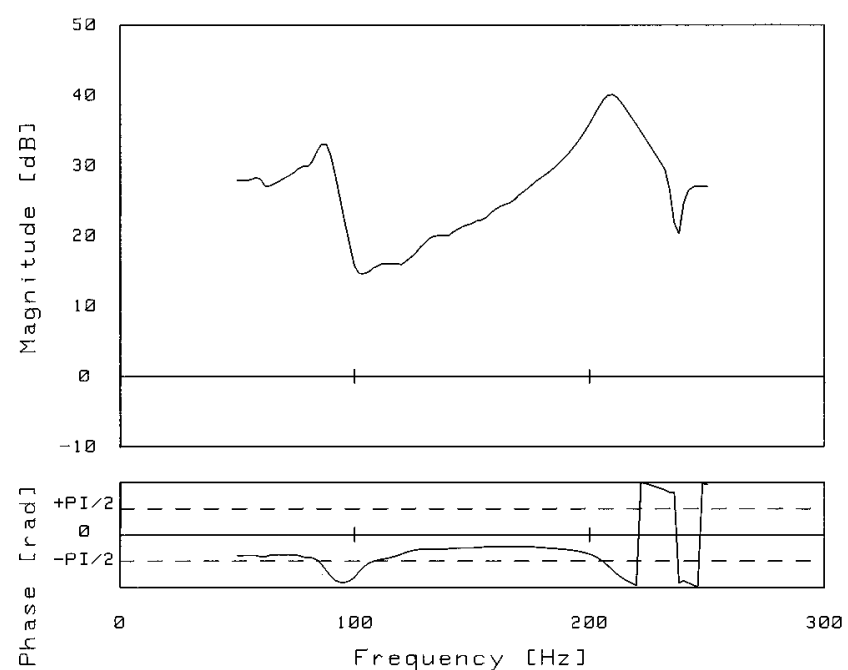

FIG. 4. A measured mechanical response of the lips. The value of the mechanical response magnitude (decibel representation) is expressed in arbitrary units. The value of the phase is expressed in radian.

the force applied to the lip. Because of the construction of the artificial mouth and to keep the embouchure constant during the measurement, the mouthpiece remains in position during the measurement. The frequency range used is below the resonance frequency of the mouthpiece ( $\mathrm{Fm}$ $=545.6 \mathrm{~Hz}$ ). We assume that the latter does not influence too much the mechanical response measurement of the lip. To avoid degradation of the vibrometer signal through absorption in the transparent box wall, the laser is focused on the lip through the mouthpiece tube. The vibrometer detects the velocity of the vibration of the lip along the axis of the laser, which is the axis of the mouthpiece in our case (longitudinal vibration). In order to derive the mechanical response as defined below, we need the lip displacement. Thus after the experiments the velocity measurements are divided by $j \omega$ to obtain the displacement results.

\section{Results}

The mechanical response of the lip is the response of the longitudinal lip displacement (in the flow direction) to the driving pressure as a function of the frequency. On the curve presented in Fig. 4 we choose the lip frequency Flip (210 $\mathrm{Hz})$ as the frequency where we have the most pronounced resonance (highest magnitude) with a phase equal to $-\pi / 2$. Incidentally, a phase equal to $-\pi / 2$ at the resonance corresponds to the "outward beating reed" behavior according to the model of Elliot and Bowsher (1982).

Testing the artificial mouth, we have observed that the most efficient parameter to control the embouchure is the position of the mouthpiece relative to the lip. This parameter controlling the geometric boundary conditions of the lip is more effective and accurate than the control parameter of the lip tension. Mechanical responses of the lip have been measured for different settings of the embouchure. For an increase of the static pressure of the mouthpiece on the lips, we observe an increase of the lip frequency Flip from 120 to 260 
$\mathrm{Hz}$. These frequencies are compared with playing frequencies following an experimental procedure described in the next section.

\section{COMPARISON OF TUBE RESONANCE, LIP RESONANCE, AND PLAYING FREQUENCIES}

\section{A. Experimental procedure}

Once the mouthpiece is fixed in position, for a particular setting of the embouchure, the experimental procedure is carried out as follows:

(1) We generate a stable sound with the mouthpiece alone. This is done by a slow increase of the supply pressure until stable buzzing of the lip is achieved. We measure the corresponding fundamental oscillation frequency (the played

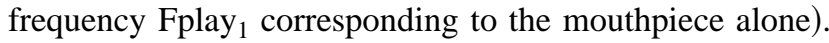

(2) We place the trombone on the mouthpiece. We repeat the procedure described in (1) and we measure the fundamental oscillation frequency (the played frequency Fplay 2 corresponding to the trombone and the mouthpiece).

(3) The air supply is switched off, the trombone is dismantled, and the source of sound (the loudspeaker) is switched on. We perform the mechanical response measurement on the lips. The mechanical resonance frequency of the lip is measured (the lip frequency Flip).

(4) We repeat the operation (1) to ensure that the embouchure has remained constant during the entire procedure. We then modify the embouchure and repeat the complete procedure.

Notice that we have performed the mechanical response measurement of the lip with the air supply switched off to have a direct characterization of the mechanical behavior of the embouchure, assumed uncoupled to the acoustic resonator in this case. To do the same kind of measurement with nonzero mean flow could be an interesting and useful extension of the results described in this paper. In this way, we could see how the coupling between the mechanical oscillator (the lip) and the acoustical oscillator (the mouthpiece, for example) due to the airflow at the lip orifice, modifies the eigenfrequencies of the coupled system, and consequently modifies the Flip estimated from the vibrometer measurement of lip vibration.

\section{B. Results and discussion}

We have measured three frequencies for each embouchure: the played frequencies Fplay ${ }_{1}$ and Fplay ${ }_{2}$, and the lip frequency Flip. It is useful to present the played frequencies as functions of the lip frequency. The results with two kinds of acoustical resonators are presented, respectively: the mouthpiece alone (Fig. 5), and the trombone with its mouthpiece (Fig. 6). Please note again that we have simplified the artificial lips using only one lip: the second half of the mouthpiece entrance, corresponding to the removed lip, is closed with a plate.

Figure 5 plots the frequency of the self-excited sound Fplay against the lip eigenfrequency Flip. As expected from the case of buzzing lips, the sound frequency increases with the lip frequency. Some of the results are, however, unexpected. The playing frequency is always below the resonance

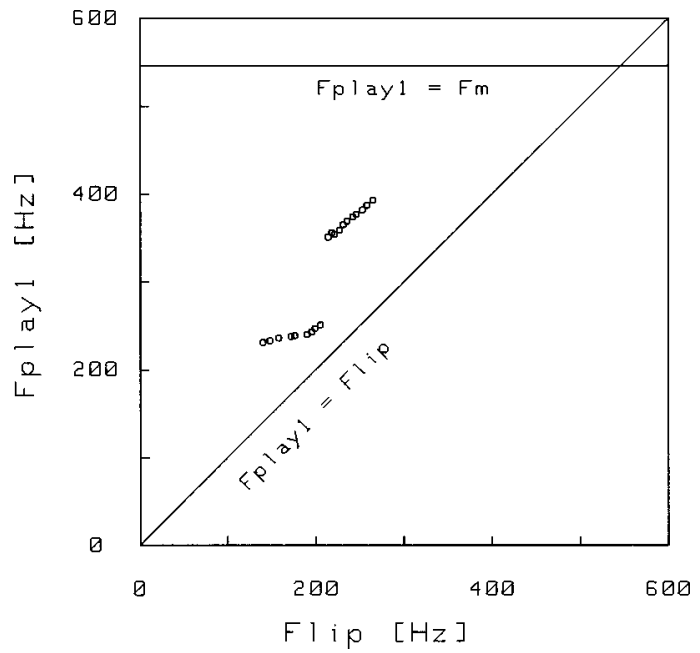

FIG. 5. The played frequency Fplay1 as a function of the lip frequency Flip. The resonator is the mouthpiece alone (Bach model Megatone $6^{1 / 2} \mathrm{AM}$ ), its resonance frequency is $F m=545.6 \mathrm{~Hz}$.

frequency of the mouthpiece and always above the lip frequency. At first sight this is inconsistent with results of the classic one mass model: according to the "inward beating reed" behavior, the playing frequency should be below both the resonance frequency and the lip frequency. According to the "outward beating reed" behavior, the playing frequency should be above both the resonance frequency and the lip frequency (Fletcher, 1979). Moreover we found with the artificial mouth a second oscillation regime (see in Fig. 5 the bifurcation between the two regimes near the frequency lip value of $210 \mathrm{~Hz}$ ) which is not predicted by a single mass model. This might be a second vibrating mode of the lip. Such a second lip mode could be a second longitudinal mode observed in the measured mechanical response (see the second mechanical resonance around $80 \mathrm{~Hz}$ in Fig. 4). It could also be a transverse mode invisible in our measurements because of the particular position of the vibrometer which measures the lip vibration only along the axis of the mouthpiece.

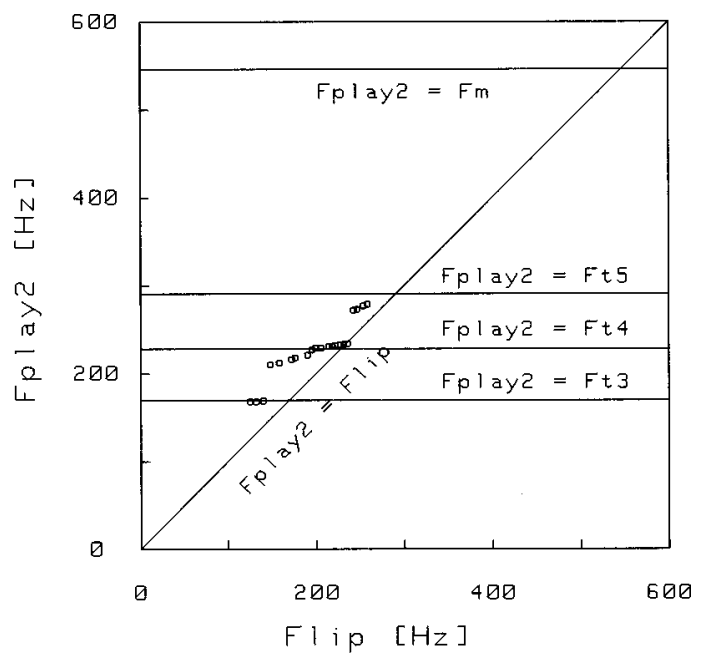

FIG. 6. The played frequency Fplay2 as a function of the lip frequency Flip. The resonator is the trombone (Courtois model 149) with its mouthpiece (Bach model Megatone $6^{1 / 2} \mathrm{AM}$ ), the useful resonance frequencies are $F t 3=169.1 \mathrm{~Hz}, F t 4=228.2 \mathrm{~Hz}$, and $F t 5=290.8 \mathrm{~Hz}$. 
At the moment such hypotheses remain unconfirmed. In view of the existence of these two buzzing regimes, using a two mass model for the lip becomes attractive.

During the experimental procedure, for each embouchure we have placed the trombone on the mouthpiece. For a variation of the lip frequency from 120 to $260 \mathrm{~Hz}$, we have obtained three notes corresponding to the resonance frequencies number 3, 4, and 5 of the trombone. The three notes played are F3, Bflat3, and D4. Figure 6 plots the frequency of the self-sustained sound Fplay against the lip eigenfrequency Flip with the resonance frequencies number 3, 4, and 5 of the trombone (the horizontal straight lines in the figure). The bisection line where Fplay is equal to Flip is also drawn. Between adjacent resonance modes, frequency gaps that represent the mode transitions between two adjacent notes are found. But in each resonance mode, the playing frequency Fplay does not take a constant value. Instead, there is a frequency range of Fplay where a self-oscillation is possible and where Fplay gradually ascends with an increase in Flip. This behavior of the artificial mouth is quite similar to that observed for a human trombone player. Is it possible to draw a conclusion about the lip model from these experimental results? Again, the results are not compatible with the basic one-mass model: the played frequencies are sometimes below and sometimes above the resonance frequencies.

Even if these experimental results on artificial buzzing lip cannot be directly linked with the simplified one-mass or two-mass models, it is interesting to perform a qualitative comparison with previous experimental results obtained for real brass players. As observed by Chen and Weinreich (1996), brass players are able to pull the pitch of the played note both well above and well below the resonant frequency of the instrument (bend technique); we have observed the same kind of results with the artificial buzzing lip coupled with a trombone (Fig. 6). This confirms that the simple onemass model (outward or inward beating) does not suffice. But we should note that a one-mass model such as that proposed by Elliot and Bowsher (1982) can predict both an inward and an outward behavior: As remarked by Campbell and Greated (1987), the two forces acting on the mechanical oscillator with one degree of freedom have opposite signs, so by making one or the other force dominate, the desired type of behavior can be obtained. The two forces are the pressure difference between the mouth and the mouthpiece and the Bernoulli pressure at the lip orifice. In the same way, the one-mass model of Elliot and Bowsher is compatible with the observations of Yoshikawa (1995) of the transition from the outward-striking oscillation in low modes to the upwardstriking oscillations in high modes. On the other hand, the experimental results obtained with the artificial buzzing lip coupled with a mouthpiece alone (Fig. 5) seem not to be easily compatible with a one-mass model, because of the existence of two different buzzing regimes. In this case, to describe the essential features of the oscillatory behavior of the lips, it seems that we need a two-mass model similar to that used to describe vocal fold motion (Ishizaka and Flanagan, 1972; Pelorson et al., 1994) or snoring (Auregan and Depollier, 1995). Direct visualizations have already highlighted two degrees of freedom (Martin, 1942; Jorno, 1996;
Copley and Strong, 1996), and Gokhshtein (1981), using a subtle and interesting visualization technique, observed that in the low register the human lips execute a wavelike motion. Moreover this two-mass model is attractive from the viewpoint of the trombone player: it could explain the ability to generate self-sustained lip oscillations over a large range of frequencies without the mouthpiece and the instrument (the "buzz technique"). We are convinced that additional experiments on other artificial mouths in progress (Vergez and Rodet, 1997; Cullen et al., 1998) will in the near future provide a better understanding of the buzzing lips behavior. Incidently such experiments will supply parameter values for the time simulations of brass instruments.

\section{ACKNOWLEDGMENTS}

We would like to aknowledge D. M. Campbell, J. Cullen, J. P. Dalmont, A. Hirschberg, and R. Msallam for helpful discussions about acoustics of brass instruments and for comments on this work.

Adachi, S., and Sato, M. (1996). "Trumpet sound simulation using a twodimensional lip vibration model,' J. Acoust. Soc. Am. 99, 1200-1209.

Aurégan, Y., and Depollier, C. (1995). "Snoring: linear stability analysis and in-vitro experiments,', J. Sound Vib. 188, 39-54.

Backus, J. (1963). "Small-vibration theory of the clarinet,', J. Acoust. Soc. Am. 35, 305-313.

Backus, J. (1976). "Input impedance curves for the brass instruments,' J. Acoust. Soc. Am. 60, 470-480.

Bailliet, H., Pelorson, X., Richardson, B., and Lallouache, T. (1995). "Lip vibration and pressure recordings during french horn playing," in Proceedings of the International Symposium on Musical Acoustics, Dourdan, France (Société Française d'Acoustique, Paris), pp. 23-28.

Beauchamp, J. W. (1980). "Analysis of simultaneous mouthpiece and output waveforms,' Audio Engineering Society, preprint No. 1626, pp. 111.

Campbell, D. M., and Greated, C. (1987). The Musician's Guide to Acoustics (Dent, London).

Caussé, R., Kergomard, J., and Lurton, X. (1984). “Input impedance of brass musical instruments-Comparison between experiment and numerical models,', J. Acoust. Soc. Am. 75, 241-254.

Chen, F. C., and Weinreich, G. (1996). "Nature of the lip reed,' J. Acoust. Soc. Am. 99, 1227-1233.

Copley, D. C., and Strong, W. J. (1996). "A stroboscopic study of lip vibrations in a trombone,'” J. Acoust. Soc. Am. 99, 1219-1226.

Cullen, J., Gilbert, J., Campbell, D. M., and Greated, C. A. (1998). “Acoustical measurements in resonators driven by an artificial mouth, oscillation threshold behavior,' in Proceeding of the International Symposium on Musical Acoustics, Seattle (Acoustical Society of America and Catgut Acoustical Society), pp. 141-146.

Dalmont, J. P., and Bruneau, A. M. (1991). "Acoustic impedance measurement: plane-wave mode and first helical-mode contributions," J. Acoust. Soc. Am. 91, 3026-3033.

Dalmont, J. P., Gazengel, B., Gilbert, J., and Kergomard, J. (1995). "Some aspects of tuning an clean intonation in read instruments," Appl. Acoust. 46, 19-60.

Dietz, P., and Amir, N. (1995). "Synthesis of trumpet tones by physical modeling," in Proceedings of the International Symposium on Musical Acoustics (Société Française d'Acoustique, Paris), pp. 471-477.

Elliot, S. J., and Bowsher, J. M. (1982). "Regeneration in brass wind instruments,' J. Sound Vib. 83, 181-217.

Elliot, S. J., Bowsher, J., and Watkinson, P. (1982). "Input and transfer response of brass wind instruments,' J. Acoust. Soc. Am. 72, 1747-1760.

Fletcher, N. H. (1979). "Excitation mechanisms in woodwind and brass instruments,' Acustica 43, 63-72.

Gazengel, B. (1994). "Caractérisation objective de la qualité de justesse, de timbre et d'émission des instruments à vent à anche simple' (text in french), Doctoral thesis, Université du Maine, Le Mans, France.

Gilbert, J. (1991). "Etude des instruments de musique à anche simple: extension de la méthode de'équilibrage harmonique, rôle de l'inharmonicité 
des résonances, mesure des grandeurs d'entrée'" (text in french), Doctoral thesis, Université du Maine, Le Mans, France.

Gilbert, J., and Petiot, J. F. (1997a). "Non-linéarités dans les instruments à vent de type cuivre", (text in french), Actes du 4ième Congrès Francais d'Acoustique, Marseille (Société Française d'Acoustique, Paris), Vol. 1, pp. 641-644.

Gilbert, J., and Petiot, J. F. (1997b). "Brass instruments, some theoretical and experimental results,' Proceedings of the International Symposium on Musical Acoustics (Institute of Acoustics, London), Vol. 19, pp. 391400.

Gokhshtein, A. Y. (1981). "Role of airflow modulator in the excitation of sound in wind instruments,', Sov. Phys. Dokl. 25, 954-956.

Hirschberg, A., Gilbert, J., Msallam, R., and Wijnands, A. P. J. (1996). "'Shock waves in trombones,', J. Acoust. Soc. Am. 99, 1754-1758.

Idogawa, T., Kobata, T., Komuro, K., and Iwaki, M. (1993). "Nonlinear vibrations in the air column of a clarinet artificially blown,' J. Acoust. Soc. Am. 93, 540-551.

Ishizaka, K., and Flanagan, J. (1972). "Synthesis of voiced sounds from a two-mass model of the vocal cords," Bell Syst. Tech. J. 51, 1233-1268.

Jorno, D. (1996). "Etude théorique et expérimentale de l'auto-oscillation des lèvres en présence d'un couplage acoustique', (text in french), Rapport du DEA ATIAM, Institut de la Communication Parlée, Grenoble, France.

Juin, F. (1996). "Simulations numériques d'instruments à vent de type cuivre' (text in french), Rapport du DEA d'Acoustique Appliquée, Université du Maine, Le Mans, France.

Martin, D. W. (1942). 'Lip vibrations in a cornet mouthpiece,' J. Acoust. Soc. Am. 13, 305-308.

Meynial, X. (1987). "Systèmes micro-intervalles pour instruments à vent à trous latéraux; Oscillation d'une anche simple couplée à un résonateur de forme simple" (text in french), Doctoral thesis, Université du Maine, Le Mans, France.
Msallam, R., Dequidt, S., Tassart, S., and Caussé, R. (1997). "Physical model of the trombone including non-linear propagation effects," Proceedings of International Symposium on Musical Acoustics (Institute of Acoustics, London), Vol. 19, pp. 419-424.

Pelorson, X., Hirschberg, A., Van Hassel, R. R., Wijnands, A. P. J., and Auregan, Y. (1994). "Theoretical and experimental study of quasisteadyflow separation within the glottis during phonation. Application to a modified two-mass model," J. Acoust. Soc. Am. 96, 3416-3431.

Piau, L. (1997). “Etude expérimentale du comportement d'instruments de musique en situation de jeu, Bouche artificielle version 2', (text in french), Rapport de recherche, Ecole Centrale de Nantes, France.

Pratt, R. L., Elliott, S. J., and Bowsher, J. M. (1977). "The measurement of the acoustic impedance of brass instruments,' Acustica 38, 236-246.

Rodet, X., and Vergez, C. (1996). 'Physical models of trumpet-like instruments detailed behavior and model improvements,' Proceedings of ICMC96, Honk-Kong (unpublished).

Saneyoshi, J., Teramura, H., and Yoshikawa, S. (1987). "Feedback oscillations in reed woodwind and brasswind instruments," Acustica 62, 194210.

Strong, W. J., and Dudley, J. D. (1993). "'Simulation of a player-trumpet system," Proceedings of the Stockholm Music Acoustics Conference (Royal Swedish Academy of Music, Stockholm), No. 79, pp. 520-524.

Vergez, C., and Rodet, X. (1997). "'Model of the trumpet fundtionning: real time simulation and experiments with an artificial mouth," Proceedings of International Symposium on Musical Acoustics (Institute of Acoustics, London), Vol. 19, pp. 425-432.

Wilson, T. A., and Beavers, G. S. (1974). "Operating modes of the clarinet,', J. Acoust. Soc. Am. 56, 653-658.

Yoshikawa, S. (1995). "Acoustical behavior of brass player's lips,' J. Acoust. Soc. Am. 97, 1929-1939. 